\title{
Research on Digital Intelligent Integration at the User Side of Modern Urban Tram Green Energy Technologies
}

\author{
Yan Lan \\ Shanghai Urban Construction Design \& Research Institute (Group) Co. Ltd. Shanghai, China \\ Email address: \\ Yanlan-99@163.com \\ To cite this article: \\ Yan Lan. Research on Digital Intelligent Integration at the User Side of Modern Urban Tram Green Energy Technologies. International \\ Journal of Transportation Engineering and Technology. Vol. 4, No. 2, 2018, pp. 24-30. doi: 10.11648/j.ijtet.20180402.11
}

Received: May 23, 2018; Accepted: June 19, 2018; Published: July 21, 2018

\begin{abstract}
With the loss of the advantage of the demographic dividend, investment and cost of Chinese modern industrial life cycle will be subject to more attention, thus, modern streetcar security operations electrification, automation and digitization increasingly seem urgent importance. Based on the positive line in Jiangsu Province, Suzhou Modern Line 1 tram depot and project scheduling control center for digital applications electrification project, design of digital integrated intelligent integration of the key technology development programs. Breaking the big railway, subway semi-automated routine traditional design proposed digital, green, low-carbon technologies of the new design concept, creating a modern Chinese city tram electrification digital intelligence information systems security operation of a new design pattern.
\end{abstract}

Keywords: Digital Intelligent, Integration, Lifecycle, Interconnection Technology, Create, Innovative, Green, Low-Carbon Design

\section{Introduction}

A modern city tramway + interoperability of digital intelligent integration system design case.

Currently, the focus on the future development of the international industry is electrification, automation and digitization. These initiatives are designed to strengthen the integration of mechanical and electrical systems of digital design technology core competitiveness. It is our international strategy around this idea, in the mechanical and electrical design, Suzhou New District Modern Tram Line 1 project, using a digital Industry 4.0 electromechanical digital integrated information system interoperability design.

Suzhou New District modern design content tram Line 1 Project weak control system. Project line length $18.19 \mathrm{~km}$, the starting point of the line length is Dragon Road station and finish at Suzhou park station. Current project all located station 7 (Eco-City station, Long Hill Road station, station management committee, White Horse Stream station, the White Horse Stream ecological park station, New Park Station, Suzhou Park Station). Vehicle base is located in Taihu Lake Road on the south side in a large Yangshan, the future will have to shoulder the dispatch center operations management 3, 4 lines. Information design vehicle base group of buildings covers Suzhou modern streetcar line 1-line operators, maintenance, scheduling and control center staff offices, duty, and other needs of the entire content life. Inner vehicle base building construction design includes: comprehensive building control center, library maintenance, do not fall round turnings library, library wash, paint shop, garage, dangerous goods, substations, underground parking, guard duty room and other buildings, with a total construction an area of about $49910 \mathrm{~m} 2$, an area of about 9.5 hectares. We introduced modern streetcar control system design key technology industrialization digital interconnection of information systems --- central information management system, please refer to Figure 1, "Suzhou New District Modern streetcar line 1 network plans". 


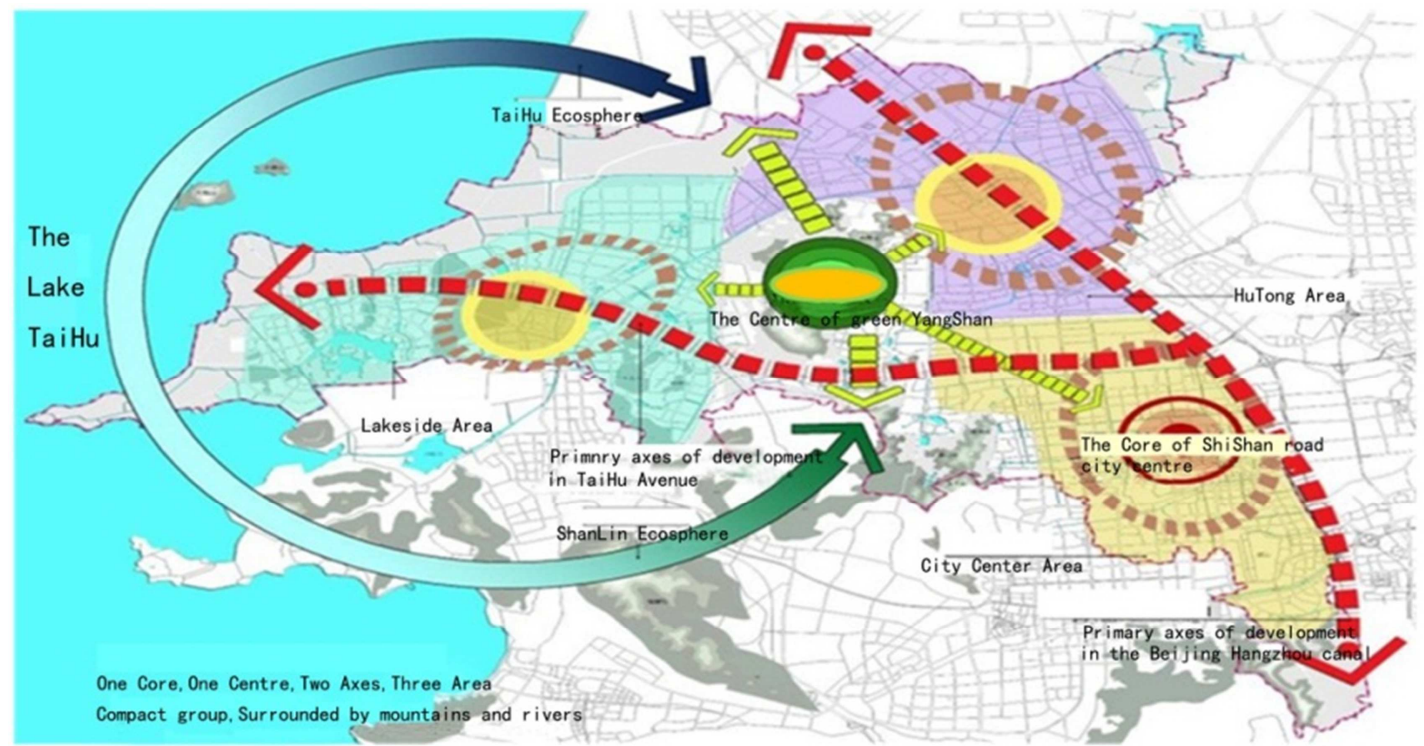

Figure 1. Suzhou New District Modern streetcar line 1 network plans.

\section{Design}

Safety dispatch operations and management system Suzhou New District Modern Tram Line 1 project, we used the interconnection of information technology, big data, network computing in terms of modern urban streetcar data acquisition applications of key technologies designed scheduling control design Center "operational control management system" intelligent integration of information systems. The goal is to better play and important role in the promotion of public transport in the safe operation of the Suzhou modern tram project, so the majority of passengers to provide more high-quality, convenient and comfortable public transport information service, operation and management of modern tram to provide a more intuitive, visual safe, reliable and stable operation of production tools provide true for the city manager, display statistics and scientific supervision of real-time data services of an important tool.
Digital Intelligent Mechatronics Interconnection System Design Program

Suzhou New District Tram Line 1 positive line and vehicle base building engineering weak control system, we have designed interconnection "control centers - large platform central information management system" system.

Intel Digital Integrated interconnection system consists of the following components: a central information management systems, network communication systems, the clock of the system, integrated control and management systems, weak construction and control system, operational dispatch management system, intelligent signaling systems, automatic fire alarm system, power monitoring systems, intelligent transportation priority systems, energy monitoring and control system, large-screen display interconnect systems, geographic information monitoring systems, repair and maintenance management system, etc. [1] and the respective systems interoperable interface part of an integrated, please detail.

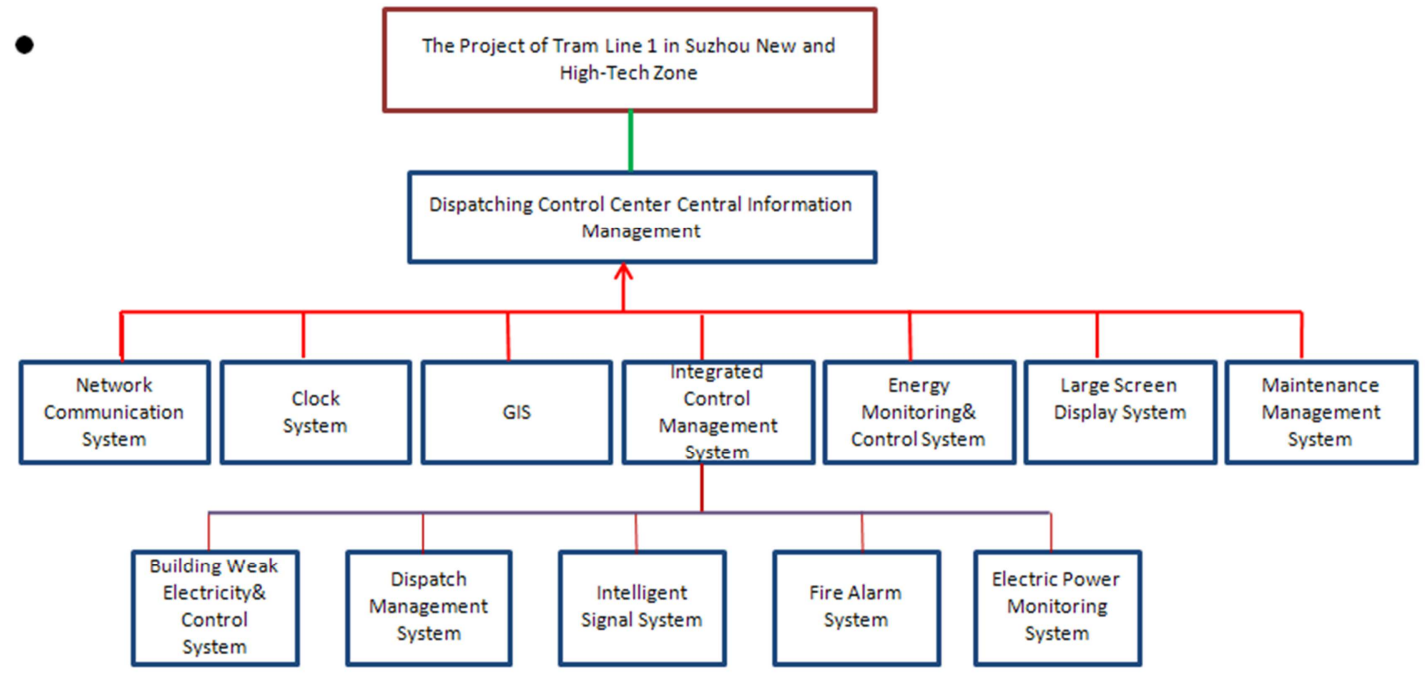

Figure 2. Intelligent mechatronics systems interconnection plan diagram. 


\section{Intelligent Mechatronics Interconnection System Block Diagram of the Program}

\subsection{Dispatch Control Center}

Dispatch control center hall is an important place of modern streetcar dispatching management personnel as well as electricity substation monitoring, control switch and other operations personnel daily work, a collection of operations scheduling, vehicle command and coordination platform, video surveillance, switch control, power monitoring, alarm disposal and other related security operations function.

\subsection{Central Information Management System 2.2}

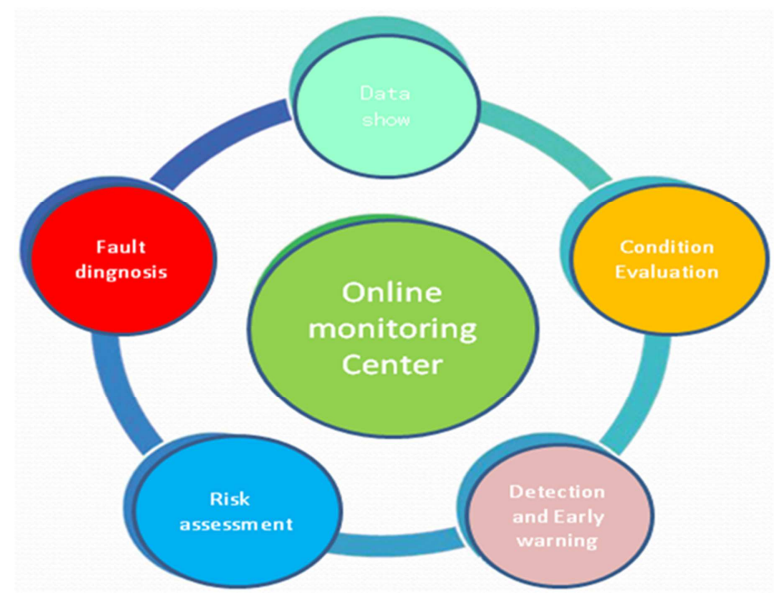

Figure 3. Central information management system function schematic.

Central information management system as the core infrastructure platform control dispatch center. It is through the various subsystems of the integrated information collection, processing and use of the data presented, integration and mining, etc., for the management agency dispatch control center provides a "digital, comprehensive, efficiency" of a visual management tool Please see.

\section{A Schematic View of the Central Information Management System Function}

\subsection{Data Center [1]}

Data Center (center room) is an important foundation and safeguard overall weak systems integrated operation efficient and reliable operation of the dispatch system, consists mainly of core network systems, databases and storage systems, backoffice services system software, GIS systems, various application servers, video surveillance server clock synchronization equipment, UPS uninterruptible power supplies.

\subsection{Integrated Network Communication System}

Suzhou New District Modern Tram Line 1 project network communication system, using a separate Gigabit Ethernet transmission "of data, voice, video," large volume of information, the program uses industrial-grade Ethernet fiber ring [3].

Computer data center network with the central information management system dispatch center, all connected to the redundant core switches, to build a new 48-core fiber optic backbone to connect to a Gigabit industrial bicyclic backbone. Please refer to

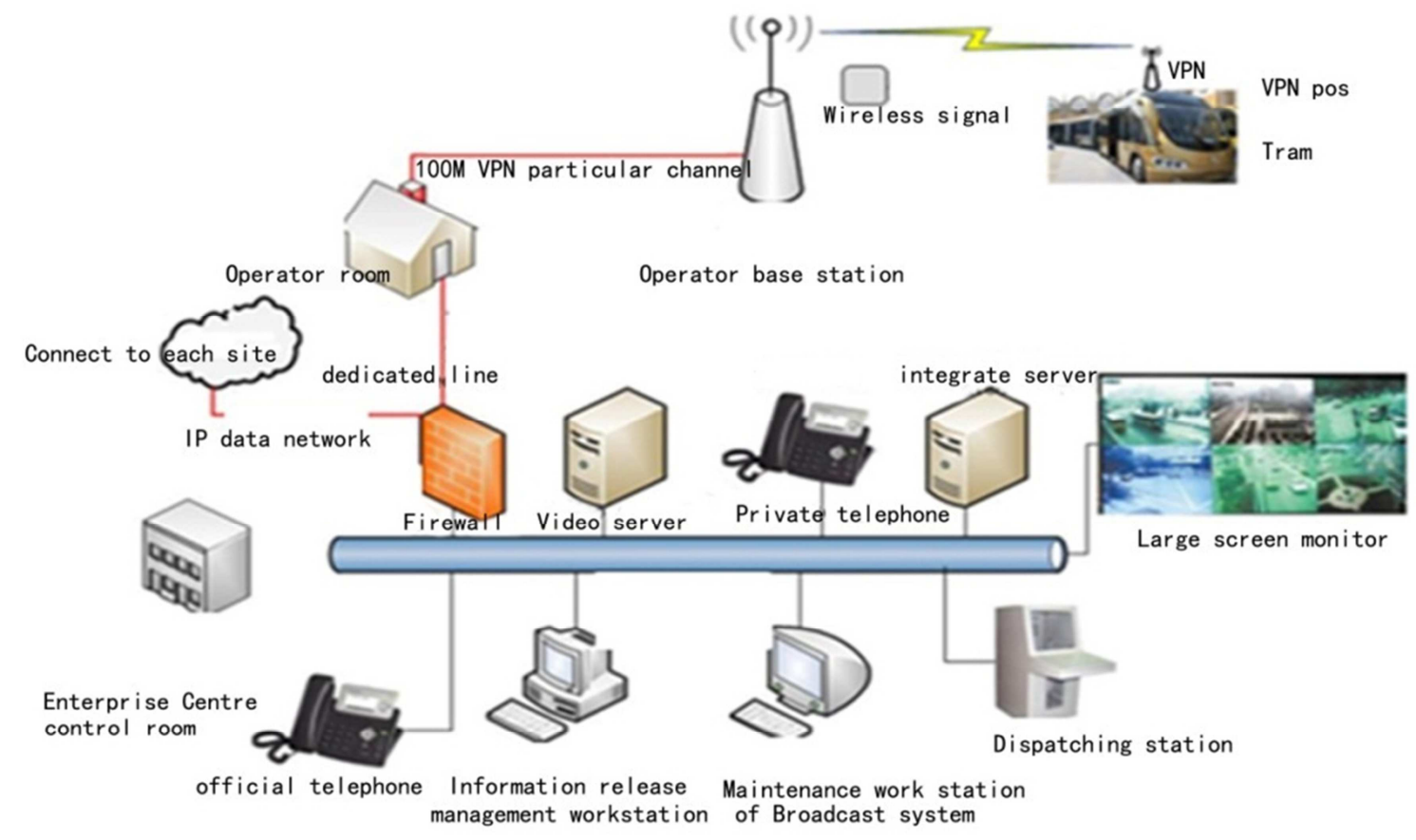

Figure 4. Integrated Communication Network System Framework General Plan. 


\section{Integrated Network Communications Framework General Plan}

\subsection{Integrated Control and Management System}

Integrated monitoring and system-level control centers to consider jointly provided in the dispatch hall operations management, set up a schedule workstation. Integrated monitoring system with the large-screen display interface system, power monitoring system can be administered to large screen for the dispatcher to view [2].

Integrated control management system is an important foundation of data management and security of the entire integrated operation efficient and reliable operation of the dispatch system, it consists mainly of core network systems, databases and storage systems, back-office services system software, various application servers, video surveillance server, clock synchronization device, UPS uninterruptible power supply and so on.

\subsection{Operation and Dispatch Management System (ODS)}

Operational dispatch management system including video surveillance systems, automotive equipment systems and other functions.

1) Operations Management System

Operational dispatch management system is the tram dispatch operations and management personnel and other operating personnel daily work place, a collection of operations scheduling, vehicle operators, site coordination, video surveillance disposal and other related functions.

Switch between control and power monitoring software system to support operational dispatchers (and other management and operational staff) of the daily work, including integrated information management, program scheduling, operations scheduling, vehicle monitoring, video surveillance and the interface subsystem.

2) Information Management Operations

Operations Information Management covers the basic information management, operations management, security management, ticket management, decision support and so on, the Line 1 tram operator's main business and major security business into the system, a unified collection, centralized management, shared use, sharing of resources and efficient use, provides a full set of operational management solution for the project.

3) Operations scheduling subsystem

(i) Vehicle Scheduling

(ii) exception handling.

(iii) staff attendance

(iv) Data Query

(v) trips Data Management

(vi) Business Data Report

(vii) Business Analysis Report

\subsection{Turnout Control, Power Monitoring Software Interfaces}

1) intelligent signaling system [2]

Intelligent signal system mainly consists of turnout and signal control system crossing signal priority system. Wherein the switch signal control system includes a main line switch control system and depot interlocking control system.

2) switch signal control system

3) Line Turnout Control System

4) crossing priority system

Signal priority control is achieved by optimizing the design of the intersection traffic signal control strategy for modern urban tram vehicle tilt signal distribution and improve vehicle efficiency in traffic intersections to ensure the right of way of the vehicle.

\subsection{Video Monitoring Subsystem (CCTV)}

Video surveillance system as a safe vehicle operation supervision, to ensure that important system line operation order, can effectively improve the quality of staff, improve the security situation of the site operations, inventory all kinds of reasons for abnormal events and responsibilities, it is necessary to fully cover the interior of the vehicle the key position inside the platform, is along the line, depot and the like.

\subsection{Information Service System}

Information service System includes a platform for passenger information service system, vehicle information service system, as well as for the passengers of the service depot system.

\subsection{Automatic Fire Alarm System}

Equipment Suzhou New District No. 1 Tram Line station did not participate in all fire linkage, the small size of the station, with reference to the relevant requirements specification does not consider setting FAS. Main substation, depot set FAS, FAS control center set up the tram line No. 1 in the parking lot depot office, serving as depot FAS dispatch center.

\subsection{Large Screen Display System}

The system design is based on proven advanced liquid crystal display technology, the system is stable, highdefinition images can be achieved, fully functional, all walks of life is the most widely used large-screen systems, clarity has been greatly improved, the consumption electric, perspective, etc. with the above system has been greatly improved, long life, easy maintenance.

\subsection{Geographic Information Systems}

Geographic information system integration geospatial framework data element mesh data, geocoding data, and real- 
time event management component data is based on monitoring information collected GIS, spatial analysis, visualization and decision support full-service basic geographic data platform, by the control center of each regulatory staff using high-end means of information, the implementation of the entire line area consolidated supervision.

Through the regional level for each monitored object of detailed information collection, and entered into the GIS database, and establish a monitoring target units of latitude and longitude geographic information database, through mobile terminals with GPS module, forming a summary of statistics from the monitoring position and monitoring point positioning, surveillance video scheduling, location and a variety of information to confirm what (portion) member regulatory specialist disposal and prevention system

\subsection{Building Weak Control System (IBMS)}

The depot building intelligent design "green" weak control management system program, a total of five system components, thirty-three subsystems, to implement the scheme for us to achieve green building information to lay a strong foundation. Please refer to.

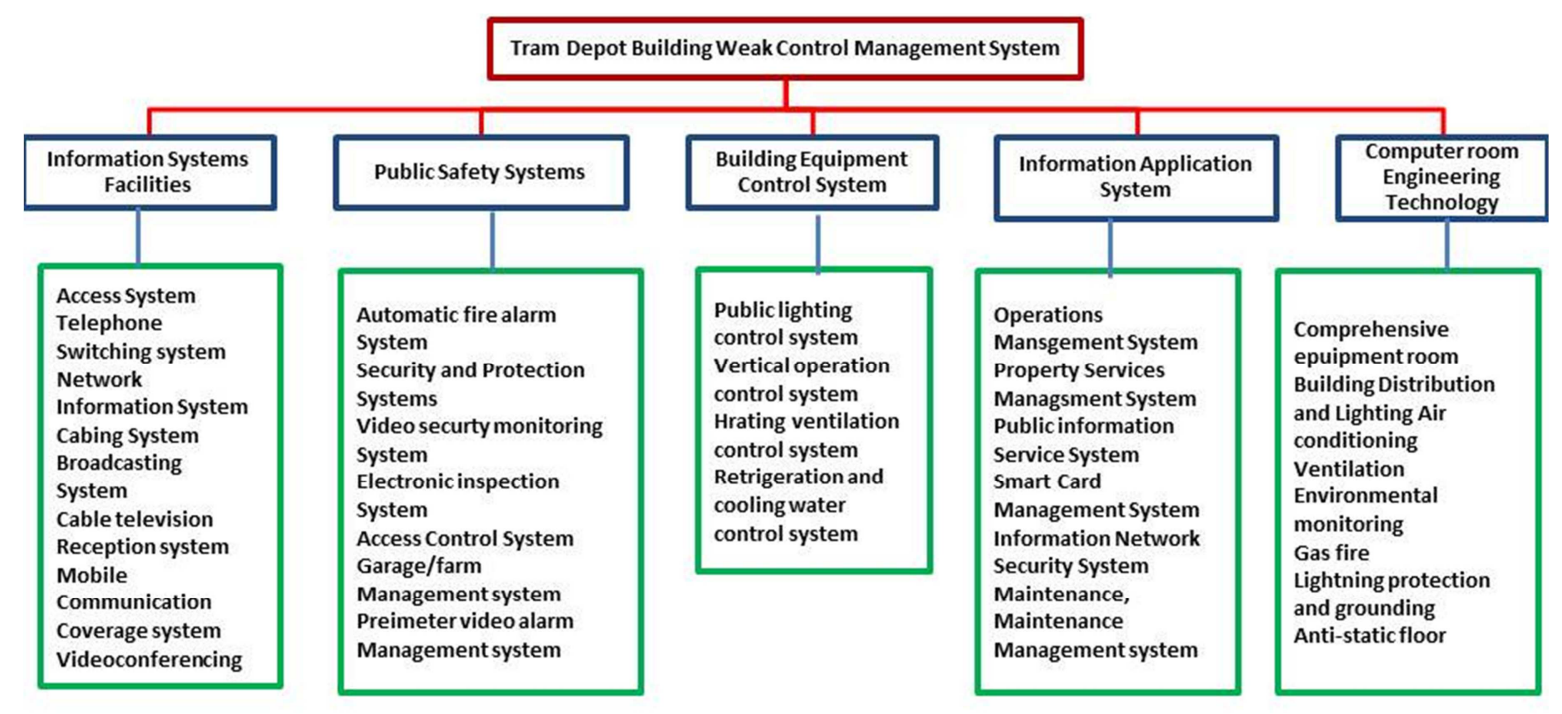

Figure 5. Intelligent building integrated" green "weak control management system diagram.

\section{Integrated Intelligent Building "Green" Weak Control Management System Diagram}

\subsection{Maintenance Management System}

1) Guarantee the normal operation of the system:

2) Improve the efficiency of maintenance and management:

3) Maintenance achieve regional linkage:

4) Implement the control center to maintain the smooth flow of management information

\subsection{Guarantee for Safeguarding Information Integration Services}

Construction of MMS system must meet the requirements, advanced, reliability and security.

\subsection{Energy Monitoring and Control Management System (PCS)}

The program we have adopted civil electrical design "Energy Monitoring and Control Management System (PCS)", the introduction of municipal public building design, and the Department of Housing has made China the highest energy-saving green building certification Samsung is the first time the civil electrical design "energy monitoring and Control management system" introduced to the modern city tram design innovative design [12].

Interface +2.6 interoperability central information management system and each subsystem

1) Internal interface [5]

Interface and Integrated Control Management System

Interface requirements and fire alarm system

Interface requirements with background music and emergency broadcast system

Interfaces and access control system

Interface requirements with car park management system

Construction equipment and interface requirements

Control Management System

Interface with Power Monitoring System

Clock interface requirements of the system

Interface requirements telephone system

2) External Interface

Suzhou City Emergency Command Center interface Interface Suzhou Municipal Traffic Information Center Interface Suzhou public security and diplomatic relations committee information center

And Suzhou Municipal Government Network Interface

Overall 3.7 Interconnection central information system and the subsystems

Our design uses a theoretical study Yang Lian and other 
compiled the "triple play key technology and construction program," the different positions of the vehicle, platform, intersection, center systems and control centers, data centers, information services, video surveillance/ automotive and other different functional subsystems for docking and integration so as to form a complete, coordinated, unified information management integrated system, built into an integrated operating system, the completion of line 1 of Suzhou tram line operations safety/ reliable, efficient, convenient and smooth system chain. Better service to enhance the image of the Suzhou municipal government management level and Harmonious City.

Two countries have made the building of "green" energysaving projects Certification Program.

\subsection{November 30, 2015 President of the People's Republic of China Xi Jinping, the Climate Conference in Paris, France Made a Commitment If the Carbon Emissions Commitments If It Is}

1) $\mathrm{CO}_{2}$ emissions peak in 2030 fell about 60 to $65 \%$;

2) accounted for about $20 \%$ of non-fossil fuels in primary energy consumption;

3) Forest century with 4.5 billion cubic meters increase over 2005.

And many times, that you want in the thirteenth five-year plan, the development of green transportation.

\subsection{China Has Obtained 4-star Green Energy Efficient Building Projects}

Community greening rate of $>38 \%$

The average energy saving rate of $>58 \%$

Saving rate of $>15.2 \%$

Recycled materials $>7.7 \%$

As of December 2014, the country has named its green building rating logo 498 projects with a total construction area of 98.7 million square meters.

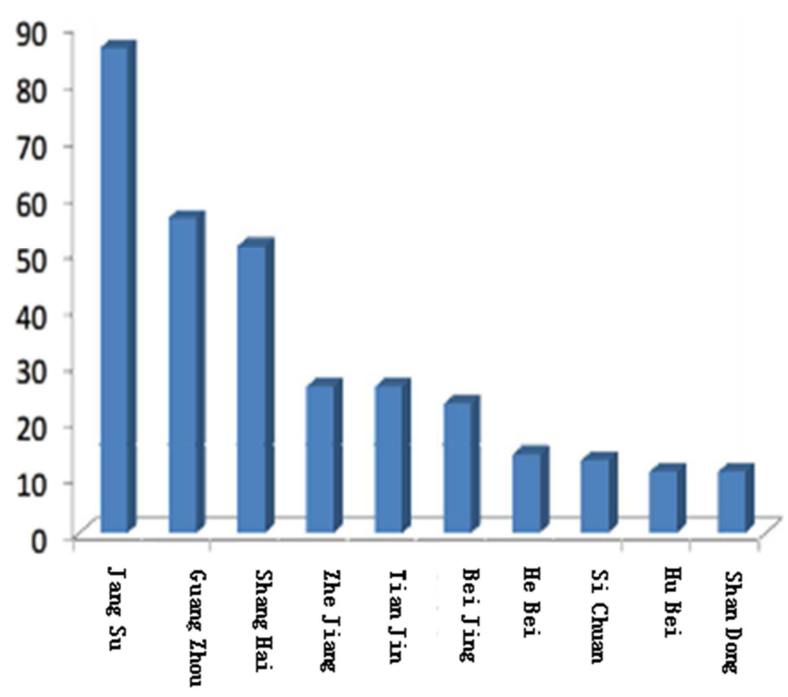

Figure 6. Has achieved national green building certification program bar graph ranking.
The rapid development trend of green building green building projects in Figure provinces ranking number (deadline 2014), please refer to Figure 6, "the country has achieved certified green building project ranked the bar graph."

High-tech Zone in Suzhou City, Jiangsu Province, China achieved a modern streetcar project Department of Housing and green Samsung EEB highest certification.

Suzhou City, Jiangsu Province, is the largest national demonstration project obtained, the number of green buildings in the country are among the best provinces. We design Suzhou modern tram lines No. 1, according to the technical requirements for "green" public building integrated intelligent transportation line network of "green energy" operational management system's design. First, follow the national and local "green" standards, as well as energy conservation government and relevant departments of the actual specific requirements of the design in accordance with Samsung's green building national standard. From planning and design at the beginning of "energy conservation and ecology," the purpose of research and development throughout the building vehicle base of a building. In the design of our energy saving 'reductions and efficiency principles in the Suzhou New District No. 1 Modern tram line do to reduce energy consumption, energy conservation in public buildings have been fully reflected in strategic Keane Save people efficiency of operation and maintenance. Hightech Zone and also promote the formation of "green" public transport network in Suzhou City, multi-level mode, play to the overall effectiveness of the public transport network. Showing a "green energy" wind Suzhou New District, Suzhou tram depot building.

Our engineering feasibility study stage design at the outset in accordance with the evaluation criteria identified and Samsung grade Chinese green building has been designed. In the planning, engineering, preliminary design phase of the efforts to achieve real conservation land, energy conservation, water conservation, material conservation, protection of the environment. Leading the modern city tram public construction projects played an exemplary high level of precedent. It has been highly praised the leadership of the State Ministry of Transportation Division, and the Suzhou New District Line 1 modern streetcar weak central information system defined as demonstration project.

I was in hospital design Suzhou New District No. 1 line tram vehicle base building complex, the comprehensive research and development buildings in the building at the highest of China Ministry of housing construction the highest level of green certification Samsung design criteria. And, in the "three-star green building" certification at the highest level of May 17, 2014 the State Department of Housing and approval, Samsung green building network publicity, and modern streetcar owners Suzhou New District in the first Municipal Engineering Jiangsu provincial Energy Office to obtain a corresponding economic subsidy.

On May 17, 2014, it was certified by the National Ministry of Housing and Urban-Rural Development as the highest- 
ranking "three-star green building" certification, publicized at Samsung Green Building Network.

\section{Conclusion}

In the past we design public infrastructure projects due to subway and light rail bottlenecks in communication technology subject. Only in accordance with local automation technology an integral part of the separate system. Now our communications technology has developed to a fiber optic system, Wi-Fi system, 4G system, completely solve the bottleneck of the key technologies of large data communications system traffic. So, we designed "digital intelligent mechatronics interconnection system design" with a "Wireless \& Cellular Telecommunications Third Edition (US)" theory is based on an integrated dispatch control operator need information management, showing a network of digital mobile, operators of the new features of wisdom, through the establishment of large-scale information collection and information integration platform to do big data. The use of artificial intelligence, big data, networking, cloud computing and other new information technology software platform, integrating modern streetcar project security operations support system. More computing application of information technology in-depth development to the cloud. To establish a "central information management system" in the control centers collected a large number of modern buildings and tram security operations require security, stability, the whole point of time Comprehensive data traffic operations, extending the life of the modern trams security operating cycle time. We through the central information technology software for a variety of data classification, statistics, analysis integration, obtain safe, stable and efficient operation instruction, guide dispatchers through digital network management, truly reductions and efficiency, reduce operational and workload and maintenance costs, to avoid a large number of security risks and greatly reduce the economic cost of manufacturing operations. Suzhou New District Line 1 modern streetcar project in October 26, 2014 adopted a formal acceptance, operations a year. "Interoperability + digital intelligent integration of modern tram in the city of applied technology" design, to achieve an intelligent, comprehensive information line network integration. Software platform interoperability energy information management system to achieve real-time cloud computing open software system, the accumulation of the next big data integration and sustainable development, access to first-hand information. For the future implementation of the new mechanical and electrical equipment access, integration of intelligent energy-saving projects, ecological reduction, lean management can truly reductions and efficiency, making the modern tram transport dimension becomes more humane, more wisdom, simpler, more economical!

"Interoperability + digital intelligent integration of modern trams in the city applied technology" makes intelligent mechatronics information systems more secure, stable and reliable. And leaders at all levels of the State Department of Transportation Secretary highly recognized and praised in the November 21, 2014. Suzhou Modern streetcar project was listed as the No. 1 model lines and establish a modern Chinese city tram interoperability information software platform and energy management systems for monitoring the success of the demonstration project.

\section{References}

[1] Yang Lian "triple play of the key technologies and building programs" [M] Beijing People's Posts and Telecommunications Press, 2011: 150-196.

[2] On Wu Qi urban rail traffic signal and communication systems [M] Beijing: China Railway Publishing House, 1998: 20-58.

[3] (US) William C. Y. Lee Wireless \& Cellular Telecommunications Third Edition [M] Beijing Tsinghua University Press, 2008: 759-790.

[4] GB/ T50314-2015 Intelligent Building Design Standards [s] Beijing China Planning Press 2015.

[5] CJJ/ T 106-2010 municipal supervision and management information systems technical specifications [s] Beijing China Building Industry Press 2010.

[6] GB/ T 50839-2013 Urban Rail Transit Project safety control Technical Specification [s] Beijing China Building Industry Press 2012.

[7] JGJ 243-2011 Transportation building electrical design specifications [s] Beijing China Building Industry Press 2011.

[8] JGJ/ T 307-2013 urban lighting energy-saving evaluation standard [s] Beijing China Building Industry Press 2013.

[9] GB 50736-2012 civil heating, ventilation and air conditioning design [s] Beijing China Building Industry Press 2012.

[10] CJJ 120-2008 Urban Drainage Systems Electrical Engineering and Automation Technical Specification [s] Beijing China Building Industry Press 2012.

[11] GB/ T50878-2013 industry green building evaluation criteria [s] Beijing China Building Industry Press 2012.

[12] GB/ T 50378-2014 Green Building Evaluation Standard. [S] Beijing China Building Industry Press 2014.

\section{Biography}

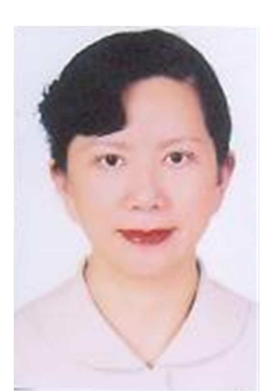

Yan Lan, Graduated from the Department of Power System Automation of North China Electric Power University, master's degree, Professor-level senior engineer; International bidding committee expert of mechanical and electrical products international bidding; Member of the National Electrical Equipment Network Communication interface Standard Committee; Shanghai Urban Construction Design and Research Institute (Group) Co., Ltd. Chief engineer of the company. 